quanto in modo agile, un aspetto del complesso pensiero di Oakeshott anche in rapporto ad altri autori (come Jeremy Bentham, sul quale scrisse, e Friedrich A. von Hayek). Speriamo possano rappresentare un invito per molti altri a confrontarsi, anche criticamente, con questo autore e con i suoi lavori.

(r.c., a.m.)

\title{
OAKESHOTT E LA TORRE DI BABELE
}

di Sergio Belardinelli*

Oakshott si occupa del famoso episodio biblico di Babele in due saggi aventi lo stesso titolo, La torre di Babele, appunto, il primo dei quali, scritto nel 1948, si trova in Razionalismo e politica, il secondo, dal medesimo titolo, e scritto nel 1979, si trova in On History and other essays ${ }^{2}$.

Nel saggio pubblicato in Razionalismo in politica, Babele è l'archetipo di una tentazione che Oakeshott considera "inevitabile nella vita umana", pericolosa per la vita degli individui e catastrofica per le comunità: "la ricerca della perfezione senza compromessi" (p. 241); ricerca che nel saggio del 1979 viene presentata come una sorta di 'nostalgia deformata' per il 'paradiso perduto'. Babele è quindi ai suoi occhi il mito nel quale il desiderio di unità del popolo ("un solo popolo e una lingua sola", dice il racconto biblico) si trasforma nel vano tentativo da parte dello stato di costringere tutta la popolazione a perseguire un medesimo obbiettivo: ritornare nell'Eden, ma senza l'impiccio dei precetti di Dio. Se nel testo biblico Babele-Babilonia, che secondo l'antica etimologia popolare significava "porta del Dio" o "porta degli dei", esprime il fallimento delle superstizioni idolatriche mesopotamiche, nei testi di Oakeshott Babele è molto di più che la civitas cupiditatis di cui egli stesso parla; si configura piuttosto

* Università di Bologna.

2 Oxford, B. Blackwell, 1983 e, with a Foreword by T. Fuller, Indianapolis, Liberty Fund, 1999. 
come monito e come pretesto per un'interpretazione non ideologica della nostra modernità.

In Razionalismo in politica, Oakeshott insiste molto sulla differenza tra la morale antica basata sull'abitudine e quella basata invece sul perseguimento di ideali morali, celebrata come "illuminismo morale" (p. 263). Le sue preferenze in proposito vanno decisamente alla morale consuetudinaria, quella che Oakeshott paragona all' arte della cucina, dove la conoscenza tecnica è combinata all'esperienza del cuoco. Tuttavia è bene tenere presente che abbiamo a che fare con 'tipi ideali' che weberianamente servono a cogliere certe specificità della realtà morale di questo o quel periodo, ma guai a ipostatizzarli. La morale antica non era soltanto abitudine, né la morale moderna è soltanto ideologia morale. La concreta moralità, secondo Oakeshott, presenta sempre una mescolanza di entrambe queste forme. Tuttavia è un fatto che nella morale moderna "la moralità del perseguimento consapevole di ideali morali è dominante" (p. 251), e come dice Oakeshott, "una morale che abbia questa forma, indipendentemente dalla qualità degli ideali, non produce altro che tensione e instabilità morale" (p. 258). Proprio come accadde a Babele, verrebbe da dire; esempio paradigmatico di un ideale altissimo (dare l'assalto al cielo!), nel quale si esprime un pericolo, una tentazione, già presente all'inizio della storia umana e per certi versi inevitabile. In altre parole, dopo la vicenda di Babele, che Oakeshott nel saggio del 1979 racconta non a caso come una sorta di storia distopica moderna (ecco il monito), è auspicabile che qualsiasi forma morale cerchi sempre di combinare abitudine e riflessione. Ai fanatici degli ideali estremi, vuoi sotto forma di morale dell'abitudine, vuoi sotto forma di morale razionale, ideologica, Oakeshott sembra contrapporre insomma il realismo della "mescolanza" (p. 243), con una chiara predilezione per una preponderanza della morale tradizionale su quella moderna, ma senza riduzionismi di sorta.

Riassumendo, Oakeshott ci dice che, dopo Babele, una certa frammentazione è fisiologica nella vita politica delle comunità. Egli ci dice altresì che, almeno su questa terra, non si può tornare al paradiso perduto, e che sarebbe catastrofico qualsiasi tentativo di realizzarne la perfezione. Ma soprattutto, ecco il punto, Oakeshott sembra dirci che questo è il contesto della nostra modernità. Guai ad assecondare certi impulsi a rimettere insieme ciò che è andato in frantumi; guai a 
sfruttare la scissione tra Dio, l'uomo e la natura susseguente alla cacciata, a vantaggio di una qualsiasi solidarietà servile per dare l'assalto al cielo. A tal proposito, all'inizio del saggio del 1979, egli sembra far trasparire anche qualcos'altro: una sorta di alternativa, moderna anch'essa, rispetto al sempre incombente peccato di Babele, generato dai figli di Cam: precisamente "La terra di Jafet", ossia l'Europa, i cui abitanti, "sebbene non immuni dalla ricaduta nella depravazione antidiluviana, si sono riconciliati con la cacciata dal Giardino, considerando la salvezza eterna un affare di Dio, non loro", diventando in questo modo gli inventori del commercio civile e accettando nel contempo l'idea di una pace precaria.

La sostanza del messaggio di Oakeshott è che Babele possa diventare un invito a rimanere nella frammentazione del mondo in cui abitiamo, piuttosto che tentare di superarla; un invito a convivere con l'incertezza e l'ambiguità di molte voci, piuttosto che pretendere di imporre una voce sola (la "lingua sola" dei babeliani). Assecondare un certo spirito vandalico rispetto alla tradizione, immaginare un ordine sociale costruito a tavolino grazie al potere, trasformare il razionalismo in uno strumento al servizio di "ideali estremi" sono tutti tratti di una modernità che io definisco "sacralizzante", di una modernità che, dopo averlo ucciso, cerca ancora la perfezione di Dio. Da Oakeshott possiamo imparare invece a mettere l'anima in pace: il paradiso lo abbiamo perduto e, con esso, abbiamo perduto anche la nostra innocenza e l'armonia di tutti con tutto. Gli uomini al plurale, non l'uomo, abitano questo mondo; la pluralità è la legge della terra; Dio vuole la pluralità, la "mescolanza", non il caos di chi, sacralizzando la propria lingua e la propria cultura (la 'lingua sola'), è incapace di vedere l'altro e le opportunità che esso nasconde, destinandosi a produrre conflitti irriducibili e instabilità. Per nostra fortuna esiste anche una modernità europea che ha accettato tutto questo. Una modernità che, pur rimanendo esposta ai rischi di cadute sempre possibili nell'antico peccato di Babele, continua a battersi per tutto questo; una modernità che ha accettato sia l'impossibilità di tornare a prima di Babele, sia la pericolosa vanità di qualsiasi tentativo di perseguire collettivamente gli obbiettivi di Dio, fossero anche i più alti, come la pace o la salvezza. E' questa la concreta possibilità della modernità europea, come dice Oakeshott, che può diventare persino una realtà storica. E' questo, direi io, l'ordine, e quasi il dono, di Babele. 